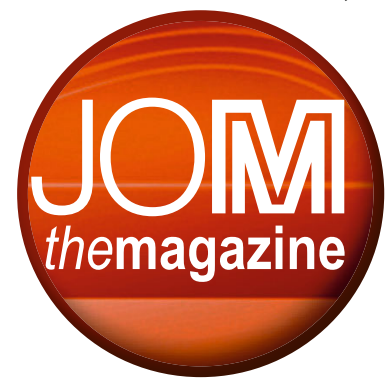

\title{
Julie Christodoulou Named Distinguished Lecturer; New Resource Preserves Engineering and Technology History
}

\section{new and noteworthy at TMS \\ Turn to this regular JOM feature for information on new TMS initiatives, updates, and overviews of TMS events and activities, as well as news from the field that impacts TMS and its members. To submit news items for consideration, contact Lynne Robinson, JOM Contributing Editor, at Irobinson@tms.org.}

\section{Julie Christodoulou to Deliver Materials and Society Distinguished Lecture}

Julie Christodoulou, chief strategist and director for Materials Science and Engineering Research at the U.S. Office of Naval Research (ONR), has been selected for the 2016 TMS-ASM Joint Distinguished Lectureship in Materials and Society Award. As the recipient of this award, Christodoulou will deliver the opening presentation at the all-conference plenary session planned for Materials Science \& Technology 2016 (MS\&T16), to be held October 23-27, 2016 in Salt Lake City, Utah.

Christodoulou was specifically cited for "visionary leadership, unwavering commitment, and tireless support of the materials community, most notably by envisioning and helping bring about revolutions in $3 \mathrm{D}$ characterization and the Materials Genome Initiative.” Presented annually, the Materials and Society Distinguished Lectureship honors an

\section{Corrections}

In the February 2016 article, "The 2016 TMS Awards: A Celebration of Substance," an incorrect affiliation was published for Ashutosh Sharma, recipient of the Extraction \& Processing Division Technology Award. Sharma is currently a research professor at the University of Seoul.

In the March 2016 article, "Meet the 2016 Young Leaders Awardees," inaccurate affiliations were published for Eun Soo Park, a Structural Materials Division Young Leaders Professional Development Awardee. Park has worked at Tohoku University, the Indian Institute of Science, Bangalore, and Lawrence Berkeley National Laboratory. individual who has served in a policymaking role for the United States and its industries.

"Over the past two decades, Christodoulou has crafted, implemented, and led multiple high-impact national initiatives. She played a key role in supporting the National Academy of Engineering study on integrated computational materials engineering (ICME), and was a core member of the team that, with the Office of Science and Technology Policy, helped turn the ICME report into the Materials Genome Initiative that was announced by President Obama in 2011," stated Kevin Hemker, Alonzo G. Decker Chair of Mechanical Engineering, Johns Hopkins University, in his letter nominating Christodoulou for the award. He continued: "Christodoulou has been a seminal member of the interagency leadership team that defined a new paradigm for materials development and placed materials science and engineering on the national agenda." On a personal note, Hemker commented that "In addition to being a materials visionary, she is a tireless advocate, extremely positive in personal interactions, and an ideal role model for us all."

Christodoulou has served in her current position with the ONR since 2007. Immediately prior to this, she was a program officer with the ONR's Naval Materials Division, having launched her career with the Navy as a metallurgist in the Naval Research Laboratory in 1992. She earned her B.S. in metallurgical engineering from the University of Texas at El Paso, her M.S. in materials science and engineering from Johns Hopkins University, and her Ph.D. in materials science from Imperial College London. In 2013, Christodoulou was recognized with the TMS Leadership Award for being "an exceptionally talented and accomplished national and international leader." 


\section{New Online Resource Preserves Engineering and Technology History}

A new Engineering and Technology History Wiki (ETHW) lets users immerse themselves in a world of technology, science, and innovation. The collaborative, encyclopedic database is cosponsored by a number of engineering societies that act as content partners, including the American Institute of Mining, Metallurgy, and Petroleum Engineers (AIME), of which TMS is a member society. This resource can be accessed at ewth.org.

With 13 categories that range from Computing and Electronics to Energy to Engineering and Society, ETHW's collections delve into the people, discoveries, and movements behind history's most innovative technological advances and encompass more than a century's worth of scientific and technological history. Included within the ETHW archives are more than 600 oral histories and more than 200 firsthand histories - with accounts from TMS members Diran Apelian, Alcoa-Howmet Professor of Engineering, Worcester Polytechnic Institute; Alex King, Director, Critical Materials Institute; Thaddeus Massalski, Professor Emeritus, Carnegie Mellon University; and Alexander Scott, retired TMS Executive Director. The wiki also contains thousands of scanned archival documents and hundreds of hours of audiovisual material.

In addition to AIME and TMS, ETHW sponsoring organizations and content partners include The American Institute of Chemical Engineers, the American Society of Civil Engineers, the American Society of Mechanical Engineers, the Society of Petroleum Engineers, and the Society of Women Engineers. These organizations teamed up with the Institute of Electrical and Electronics Engineers (IEEE) and the United Engineering Foundation to expand on the IEEE Global History Network, rebranding it as ethw.org.

\section{Best of Show for Comic-tanium ${ }^{\mathrm{TM}}$}

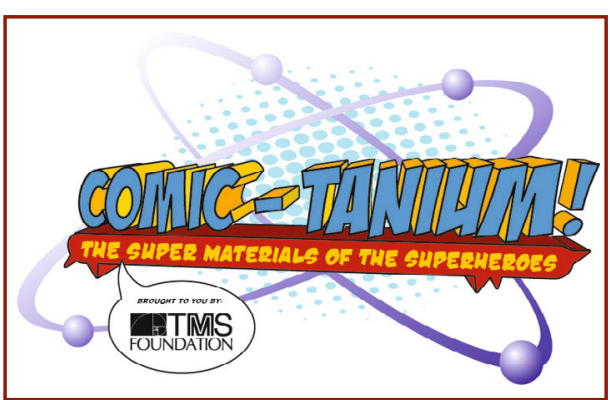

Comic-tanium: The Super Materials of the Superheroes ${ }^{\mathrm{TM}}$ _-TMS's educational exhibit linking science and technology with popular comic book characters - has earned top honors from the Pennsylvania Society of Association Executives (PASAE) for its overall excellence in educational outreach.

The PASAE Laurel Awards recognize association achievements for projects, ideas, programs, services, or events. Comictanium was selected as the first place award recipient in two categories: Large Association Meetings/Events/Education Award and the "best of show" Golden Laurel Award for overall excellence in all categories. Two TMS staff members, Mike Bazzy, Senior Manager, Marketing \&
Communications, and Dave Rasel, Media Manager and the design director for Comictanium, attended the Laurel Awards Gala on February 25, 2016 to accept the awards.

Look to the pages of JOM for information on the continuing evolution of Comictanium, which will focus on classroom outreach to educate and excite early high school students about opportunities in the minerals, metals, and materials professions.

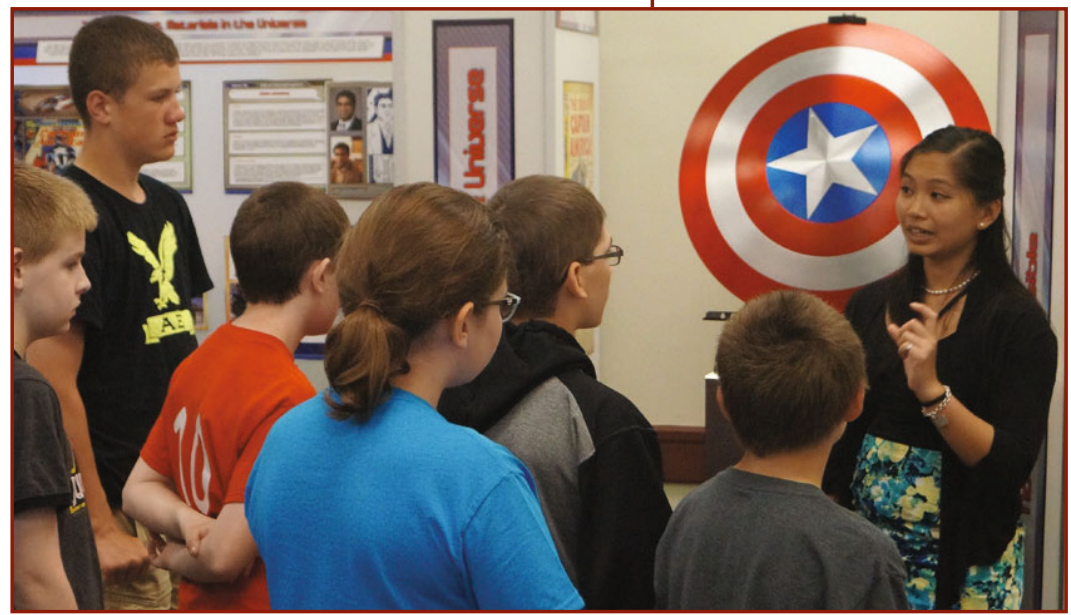

Lily Nguyen (right), TMS member and recent Carnegie Mellon University Ph.D. graduate, leads a tour of Comic-tanium for middle school students in May 2015. 


\section{TMS Welcomes New Members}

\section{Please join us in congratulating the following new TMS members, approved by the Board of Directors at its February 2016 meeting:}

Angermeier, Christoph J.; Mubea Performance Wheels, Germany

Anton, Donald L.; Savannah River National Laboratory, United States

Atwater, Mark; Millersville University, United States

Aune, Ragnhild E.; Norwegian University of Science \& Technology, Norway

Balch, Dorian K.; Sandia National Laboratories, United States

Begum, Noorzahan; Malaysia

Bernazzani, Paul; Lamar University, United States

Bhattacharya, Sudip; Carnegie Mellon University, United States

Black, Phil; Regain Materials, Australia

Boncina, Tonica; University of Maribor, Slovenia

Brauer, Samuel Louis; Nanotech Plus LLC, United States

Cao, Wanjun; United States

Chang, Yu-Min Grant; Printronix Inc., United States

Coulon, Kelly; Roux Associates Inc., United States

Iwaoka, Hideaki; Kyushu University, Japan

Crooks, James W.; United States

Decheng, Pan; China

Delplanque, Jean-Pierre R.; University of California, Davis, United States

Didenko, Tomasz; General Electric, Poland

Ding, Weinan; China

Domack, Marcia Suzanne; NASA, United States

Emge, Andrew; GE Aviation, United States

Ferron, Cesar Joe; HydroProc Consultants, Canada

Fisher, Aaron; Lawrence Livermore National Laboratory, United States

Folta, Peggy A.; Lawrence Livermore National Laboratory, United States

Garcia, Calixto I.; University of Pittsburgh, United States

Gemein, Rudolf; Outotec GmbH, Germany

Gey, Christoph; Kennametal Inc., United States

Groves, James R.; PLANT PV, United States

Chen, Zuxiong; United States

Chen, Hao; Tsinghua University, China

Chen, Lei; Mississippi State University, United States

Coffin, Charles P.; Hilti Corporation, Liechtenstein

Collazo, Andrea L.; Aleris, United States

Conde, Sandra C.; Navy, United States

Costa, Alex; Brazilian Nanotechnology National Laboratory,

Brazil

Hahn, Alison K.; U.S. Department of Energy, United States

Halloran, John W.; University of Michigan, United States

Hamerton, Richard G.; United States

Han, Heung Nam; Seoul National University, South Korea

Hetrick, Elizabeth T.; Ford Motor Company, United States

Hofmeister, William H.; University of Tennessee Space Institute, United States

Huang, Chen; Florida State University, United States

Jacobs, Tevis D.B.; University of Pittsburgh, United States

Kasprzak, Jan M.; Naval Air Systems Command, United States

Khan, Shafique; King Fahd University of Petroleum and Minerals, United States

Kim, Joo-hag; Korea Atomic Energy Research Institute, South Korea

Kim, Hyunmin; Brown University, United States

Kitchens, Robert F.; Ball Advanced Aluminum, United States

Kitkamthorn, Usanee; Suranaree University of Technology, Thailand

Lambrych, Kevin; United States

Lau, Yang Hao; Institute of High Performance Computing, Singapore

Lejaeghere, Kurt; Ghent University, Belgium

Leon, Luis; The Boeing Company, United States

Lin, Ming-Tzer; National Chung Hsing University, Taiwan

Liu, Wenying; University of British Columbia, Canada

Lucas, Matthew S.; U.S. Air Force Research Laboratory, United States

Lucio, V.B.; Mexico

Martin, Lane W.; University of California, Berkeley, United States

McDonnell, Stephen J.; University of Virginia, United States 
Miller, F. Scott; Missouri University of Science and Technology, United States

Molinero, Jorge; Spain

Montenegro, Joshua A.; RSR Technologies Inc., United States

Nasr, Mohamed H.; Allied Trading International Ltd., Egypt

O'Brien, Michael; Orange Exterminators, United States

Ogawa, Akira; Mitsubishi Heavy Industries America, United States

Pal, Soupitak; University of California, Santa Barbara, United States

Pamidi, Sastry V.; Florida State University, United States

Panfilov, Peter; Ural Federal University, Russian Federation

Paranthaman, Mariappan; Oak Ridge National Laboratory, United States

Park, Sun-Hong; Research Institute of Industrial Science and Technology, South Korea

Petford-Long, Amanda; Argonne National Laboratory, United States

Poliak, Evgueni I.; ArcelorMittal, United States

Pontikes, Yiannis T.; Katholieke Universiteit, Leuven, Belgium

Rajagopalan, Jagannathan; Arizona State University, United States

Recalde, Oscar; Universidad San Francisco de Quito, Ecuador

Ren, Fan; University of Florida, United States

Reutzel, Edward; Pennsylvania State University, United States

Roberts, Jeff; Lawrence Livermore National Laboratory, United States

Rodriguez Fernandez, Johnnatan; Brazil

Sappey, Roman; KLA-Tencor Corporation, United States

Sefton, Tim R.; United States
Shabib, Ishraq; Central Michigan University, United States

Shimizu, Kazuyuki; Japan

Simmons, Scott; Pyrotek Inc., United States

Sodera, Jay; Taber Extrusions LLC, United States

Sugar, Joshua; Sandia National Laboratories, United States

Sullivan, Jonathan F;; United States

Szczesniak, Dorota; General Electric, Poland

Vastola, Guglielmo; A*STAR Institute of High Performance Computing, Singapore

Vo, Nhon Q.; NanoAl, United States

Wagner, Sigurd; Princeton University, United States

Wan, Long; Harbin Worldwide Welding Company Ltd., China

Wang, Zhengyu; Sinoway Carbon Company Ltd., China

Wang, Zhaohui; Norwegian University of Science \& Technology, Norway

$\mathrm{Xu}$, Guang; Wuhan University of Science and Technology, China

$\mathrm{Xu}$, Haixuan; University of Tennessee; United States

Ye, Lin; Beijing Institute of Technology, China

Young, Stephen A.; University of Tennessee, United States

Yuan, Fenglin; University of Tennessee, United States

Zadpoor, Amir A.; Delft University of Technology, Netherlands

Zapke, Martin; Outotec GmbH \& Co. KG, Germany

Zhai, Huazhang; Beijing Institute of Technology, China

Zhou, Chenn Q.; Purdue University Calumet, United States

Zupanic, Franc; University of Maribor, Slovenia
TMS

Co-Sponsors

Congressional Briefing on Advanced Manufacturing

A congressional briefing on Advanced Manufacturing: Gaining the Advantage in a Fiercely Competitive Global Economy, organized by the American Society of Mechanical Engineers (ASME) and cosponsored by TMS, was held in February 2016 to discuss the role advanced manufacturing plays in supporting the U.S. economy.

Briefing speakers representing a range of government offices, agencies, and initiatives covered such topics as current programs within the National Network for Manufacturing Innovation (NNMI); translating scientific discoveries into manufacturing jobs, programs, and projects through sharing knowledge; the building of cooperative partnerships to address problems in manufacturing; and the importance of investing in research, workforces, and private and public collaborations.

The briefing was convened in conjunction with the U.S. House of Representatives' Manufacturing Caucus. 